\title{
BIOLOGY LAB-ON-A-CHIP FOR DRUG SCREENING
}

\author{
Hossein Salimi-Moosavi ${ }^{1}$, Rod Szarka², Per Andersson', Richard Smith ${ }^{2}$, D. Jed Harrison' \\ 1) Department of Chemistry, University of Alberta, Edmonton, Alberta, Canada, T6G 2G2 \\ 2) Carbohydrate Chemistry, Alberta Research Council, P.O. Box 8330, Edmonton, Alberta, Canada, T6H $5 \mathrm{X} 2$
}

\begin{abstract}
Integrated microfluidic systems for the evaluation of cell-drug interactions are described. Within a network of flow channels cells can be mxied and reacted with activators and inhibitors of cell functions in a highly controlled fashion, allowing evaluation of a chemical's potency as a potential drug with minimal consumption of the reagent. Assays for reagents that prevent calcium ion uptake in human lymphocyles are described. Measurements of cell adhesion were evaluated on-chip using a cell rolling method, which can be used to screen the ability of candidate drugs to prevent the activation of the human neutrophil cell response during the early stages of inflamatory response.
\end{abstract}

\section{INTRODUCTION}

Microfluidic chips used to study cellular events can provide the same high level of integration of reagent addition, reaction, separation and observation steps that have been demonstrated for integrated chemical and biochemical analysis systems [1-9]. The results presented here illustrate the integration of several reagent delivery steps in a biological study of cell-drug interactions, providing a biological example of the lab-on-a-chip concept. Because a microchip consumes between $0.1 \mathrm{~nL}$ and a few $\mu \mathrm{L}$ per experiment, such device volumes could provide a cost-saving advantage for work involving expensive or supply limited reagents, especially candidate compounds tested in drug-screening [9].

In the first part of this report, we demonstrate the manipulation and transport of single non-adherent cells using pressure driven flow, followed by cell reactions with agonists or antagonists, all within an integrated network of microfluidic channels. The important cellular process of activation of $\mathrm{Ca}^{2+}$ influx [10-12] within human lymphocytes was chosen to illustrate the ability of microfluidic chips to deliver cells, inhibitors and activators to confined, well defined locations, mix them, then follow the kinetics of the interactions at the single cell level with high precision. This procedure can be extended to nearly any analytical problem for which cell stains that indicate activity exist, and could ultimately serve either for drug screening or for clinical diagnostic purposes.

Another microfluidic system was developed to study cell adhesion phenomenon [12-14]. Adhesion of leukocytes is a primary step in the inflammatory response [12]. Screening tests for drugs that might reduce such responses in arthritis or other autoimmune diseases require the use of cell and animal models for accurate results, but these consume large amounts of compound. Cell rolling along a surface subject to a shear stress induced by solvent flow is an indicator that adhesion forces have been activated [13]. As an alternative, a microfluidic chip for the study of cell rolling that uses much less material per assay has been designed and tested. When a cell bearing stream flows through the test bed and is viewed under a microscope. cells that do not adhere move by too fast to be captured at video rates, while adhering cells appear to roll slowly along the surface as they stick and release, indicating adhesion and the onset of inflammatory response, as suggested by the cartoon in Figure 1. Compounds which reduce or eliminate this rolling effect are potential drug candidates $[12,13]$

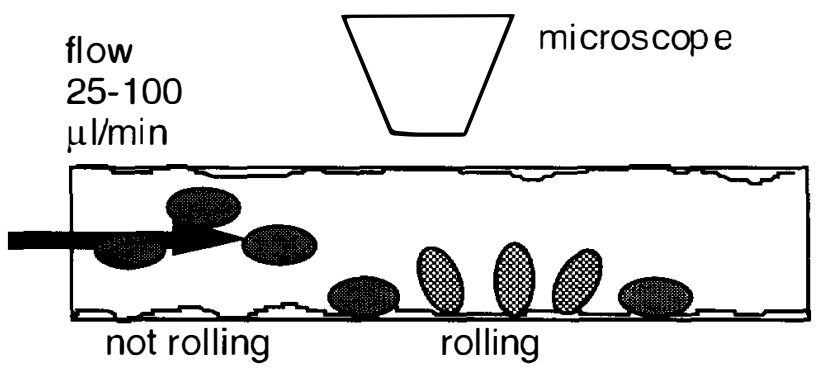

Figure 1 Cell rolling arises from a cycte of temporary adhesion and release of cells on a surface once they are activated by a biochemical signal, as illustrated in the cartoon. Non-adhering cells stream by in the solvent flow.

\section{RESULTS AND DISCUSSION}

Single Cell Flux Assays

Figure 2 shows the schematic layout of a post-column reaction device (PCRDI) microchip, utilized previously by Fluri et al. [15] for chemical reactions and separations. For our present work with non-adherent cells, solvent flow was driven by suction applied to the waste outlet, drawing solution from all four inlet reservoirs. The flow rates were designed to be controlled by the relative resistance to flow of each channel, which was a function of each channel segment length and cross section. Based on dimensions, the two side positioned inlet channels at point " $t$ " each contribute $37.5 \%$ of the flow into the incubation channel, while the middle inlet channel contributes $25 \%$. A microscope positioned 
over the mixing and detection zone, point "m", allowed observation of cells as they passed into the zone. The device was operated in a stopped flow mode, in which flow was stopped when a cell entered the detection zone. Stopped flow allowed the two unmixed zones at the intersection to diffuse into each other, initiating cell reaction with the added reagent at a well identified time and concentration. When required, cells could be stopped just before entry into the mixing zone then moved into the mixing region, so that both before and after images were easily obtained. Video images, obtained at about $16 \mathrm{~ms} /$ frame, showed that cells entered the observation zone at about $8.7 \mathrm{~mm} / \mathrm{s}$. Stopping the flow with a hand controlled syringe resulted in backward cell motion of about $5 \mu \mathrm{m}$ over the first frame, then the cell was stationary to the maximum resolution for all remaining frames over many seconds.

Numerous fluorogenic stains for the identification and quantitation of intracellular events are now available [16, 17], and are ideally suited for fluorescent detection of single cell events within these microfluidic devices. To illustrate the utility of the device we investigated the manipulation of cytostolic calcium ion levels in lymphocytes with several different activators and inhibitors. Observations of fluorescence changes downstream of mixing point $\mathrm{m}$, at which an activator can be introduced, provide a means to determine dose-response profiles and the kinetics of activation. Inhibitors can be readily introduced into the cell feedstream at point $t$, and the incubation time controlled with the

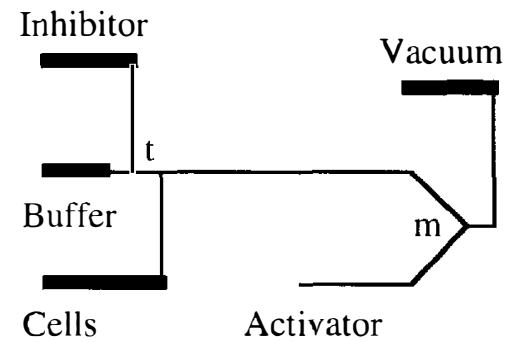

Figure 2 Flow channel layout of the Single $\mathrm{Cell} \mathrm{Ca}^{2+}$ flux chip.

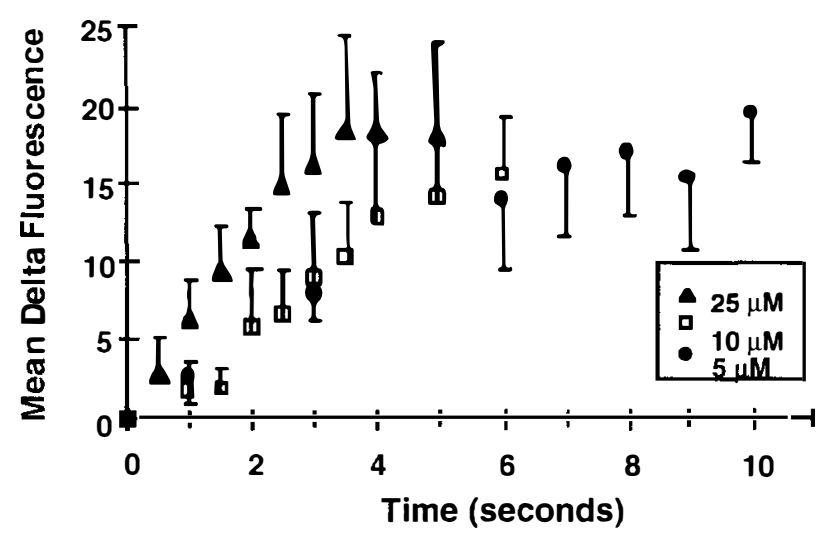

Figure 3 Dose-response curve obtained with the $\mathrm{Cd}^{2+}$-flux chip for the activation of human lymphocytes by the ionophore A23187, delivered at mixing point " $m$ " and evaluated in stopped-flow mode. Time is measured from when flow stops and mixing begins. The average change in fluorescence is shown for 6 cells at each A23187 concentration.

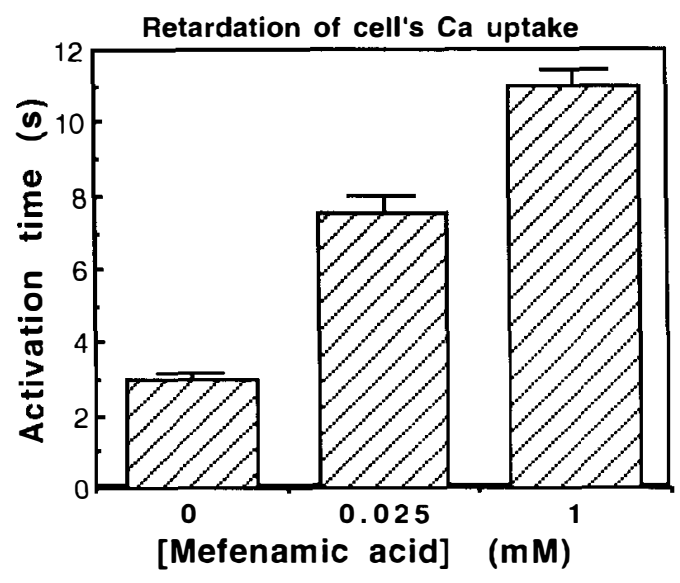

Figure $4 \quad$ Bar graph showing the increase in incubation time required for $f M L P$ activation of $\mathrm{Ca}^{2+}$-uptake by human lymphocytes, as a result of exposure to increasing amounts of the inhibitor Mefenamic acid. Mefenamic acid was introduced at point " $t$ ", incubated for $10 \mathrm{~s}$ with the cells as they were transported towards the mixing point " $m$ ", where the activator was added.

flow velocity along the incubation channel. In this way the doseresponse curves and the incubation kinetics can be readily evaluated, with the consumption of less than a $\mu$ of inhibitor solution.

Isolated Human lymphocytes were first loaded with the fluorescent $\mathrm{Ca}^{2+}$ indicator fluo-3, introduced into the chip reservoir marked cells, then transported downstream to the mixing point. To inhibit cell activation and adhesion on the glass channels 5\% fetal calf serum (FCS) was introduced to the RPMI media used to prepare all solutions introduced into the chip. Figure 3 illustrates the kinetics and the dose-response characteristics for the reaction of human $\mathrm{T}$ - and $\mathrm{B}$ - lymphocytes with the $\mathrm{Ca}^{2+}$ ionophore, A23187, which is a membrane transport agent. Typically, we see a 5 to 10 -fold increase in fluorescence over background after reaction with the activator. This is consistent with reports of increases of 2 to 40 -fold upon $\mathrm{Ca}^{2+}$ activation, depending on the cell type.

An activator/inhibitor pair was also investigated. The tripeptide, formyl-Met-Leu-Phe (fMLP) activates lymphocytes through a cascade that activates a $\mathrm{Ca}^{2+}$ ion channel, and thus shows different kinetics than A23187. During the activation step there is a concentration dependent incubation period, followed by a rapid rise in fluorescence. These kinetics are consistent with a $\mathrm{Ca}^{2+}$ channel activator. The inhibitor, mefenamic acid (MA), an anti-inflammatory drug, was used to inhibit lymphocytes activated with $\mathrm{MLP}$. MA did not permanently inhibit $\mathrm{Ca}^{2+}$ uptake, rather activation was delayed by a period of seconds. Figure 4 shows how the inhibitory period increased with increasing MA dose. These pharmacokinetics of MA inhibition are readily observed with the microchip-based stop flow format, but would be missed entirely using a method such as flow cytometry that does not include on-line mixing of reagents and cells. 
Cell Rolling and Adhesion Devices.

A microfluidic chip for the study of cell rolling that consumes much less reagent than conventional methods do has been designed and tested [12-14]. It consists of a simple $y$-mixer port, with a flow region downstream to allow observation of cell adhesion, Figure 5. However, for the studies reported hepe, the inhibitors were added to the cell suspension prior to loading on the chip, and the second part of the $\mathrm{Y}$-channel was used to introduce a selectin [18] to the microchannels, in order to coat the surfaces with a material that induces rolling. Cell rolling in a glass device with $400 \mu \mathrm{m}$ wide, $100 \mu \mathrm{m}$ deep channels can be observed with a microscope and video camera, Figure 1, when the surfaces are treated first with a selectin, and then with other appropriate coatings (see below). Experiments were performed at a flow rate of 50-60 $\mu \mathrm{l} / \mathrm{min}$, which ensures a high enough shear rate (about $800 \mathrm{~min}^{-1}$ at this flow) to mimic blood flow in a vascular capillary. An example of the rolling images is shown in Figure 6. The streaks seen are in fact non-rolling cells traveling through the field of view too fast to resolve. The cells frozen in the image are slowly rolling across the field of view, and are readily captured on video. Figures 7 and 8 illustrate quantitative analysis of the images, in terms of the number of cells rolling within the visual field ( $200 \mu \mathrm{m}$ long in the direction of flow) and the average time a rolling cell stays within the visual field.

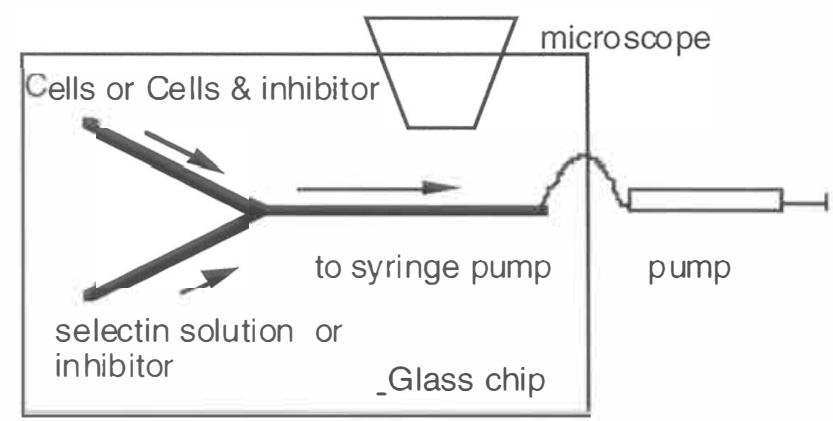

Figure 5 Flow chip design for cell rolling studies.

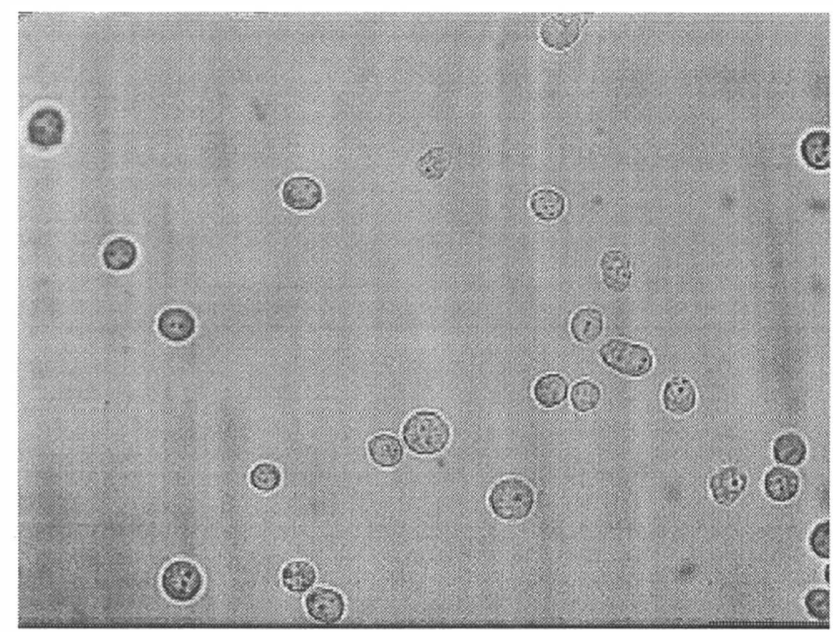

Figure 6 Rolling lymphocytes on an E-selectin coated surface. flow is from the top to bottom of the figure, a distance of $200 \mu \mathrm{m}$. Non-rolling cells move by too fast to observe.

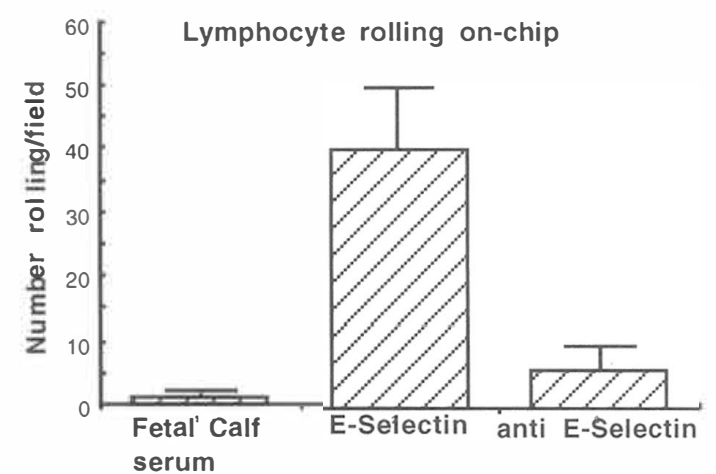

Figure 7 The number of cells rolling per field of view on a control surface (fetal calf serum coated), an active, E-selectin coated surface, and a surface subsequently treated with the antibody to E-selectin to reduce the surface activity for adhesion by binding the antibody.

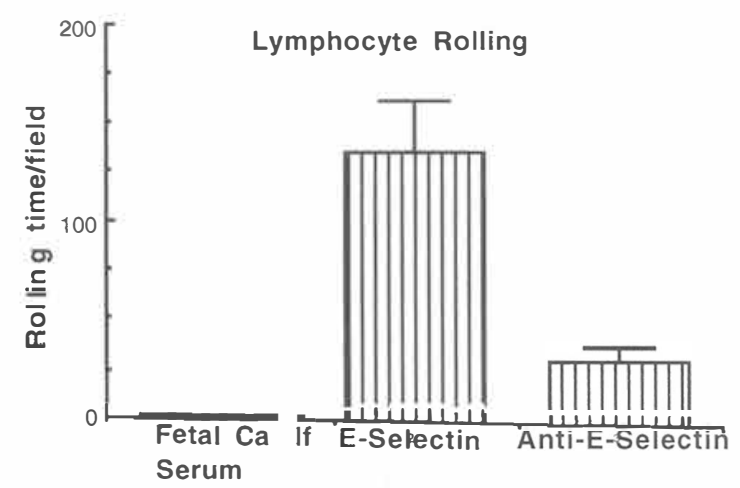

Figure 8 The time required for cells to roll across the field of view on different surfaces, for the same data as analyzed in Figure 7.

Coating the chip walls with fetal calf serum (FCS) induced no cell rolling for human neutrophils and lymphocytes. Coating the chip walls with $\mathrm{P}$ or E-Selectin (by exposure to a selectin solution for a $2 \mathrm{~h}$ period, then flushing out the solution) allowed the study of induced cell rolling for human lymphocytes, neutrophils and the immortalized human cell lines HL-60 and Jurkat. The induced rolling depended on the cell and the selectin

type. For example, Jurkats did not roll on the E-selectin surface that induced HL-60 rolling,. Human lymphocytes and neutrophils rolled on both $\mathrm{P}$ and $\mathrm{E}$-Selectin surfaces.

An adhesion inhibitor was mixed with the cells off-chip and introduced into one of the channels to determine whether cell rolling could be prevented. The antibodies to P- or E-Selectin stopped cell rolling on these surfaces, providing a control experiment to demonstrate that masking the selectin could prevent rolling. Exposure of the selectin coated surface to a flow of Sialyllewis ${ }^{x}$ or to a proprietary drug designed to prevent rolling eliminated or nearly eliminated cell rolling. 


\section{CONCLUSION}

The drug screening process requires large numbers of test be performed on a limited amount of sample. Both types of cell assay devices described here require minimal volumes of reagent per assay, on the order of 1000-fold less than macroscopic systems demand. This feature alone is a highly desirable aspect of these microchip systems. These devices are particularly important for screening in cell rolling studies, where conventional screening methods with receptor or enzyme binding assays have proved uninformative, necessitating cell rolling studies in systems that consume far too much of an untried, expensive-to-synthesize reagent. Additionally. the ability to study cell kinetics for celldrug interactions on a single cell level should prove valuable both in screening of new compounds and for advancing the science of cell biology.

\section{ACKNOWLEDGMENTS}

We thank the Natural Sciences and Engineering Research

Council of Canada for funding, and the Albert Microelectronic Centre for device fabrication.

\section{REFERENCES}

1. D.J. Harrison, K. Fluri, K. Seiler, Z. Fan, C.S. Effenhauser, A. Manz Science 261, 895 (1993).

2. S. Effenhauser, A. Manz, H.M. Widmer Anal. Chem. 65, 2637 (1993).

3. S.C. Jacobson, R. Hergenröder, L.B. Koutny, J.M. Ramsey Anal. Chem. 66, 1118 (1994).

4. A.T. Woolley, D. Hadley, P. Landre, A.J. Demello, R.A. Mathies, M.A. Northrup Anal. Chem. 68, 4081 (1996).

5. N. Chiem, D.J. Harrison, Clin. Chem., 44, 591 (1998).

6. L.J. Kricka, O. Nozaki, S. Heyner, W.T. Gorside, P. Wilding Clin. Chem. 39, 1944 (1993).

7. P. Wilding, J. Pfahler, H.H. Bau, J.N. Zemel, L.J. Kricka Clin. Chem. 40, 43 (1994).

8. D. Sobek, A.M. Young, M.L. Gray, S.D. Senturia Proc. IEEE MEMS Workshop, FL, Feb 7-10, pp 214 (1993).

9. P.E. Andersson, P.C.H. Li, R. Smith, R.J. Szarka, D.J. Harrison, Technical Digest: 1997 International Conference on Solid-State Sensors and Actuators, Transducers 97, June 16-19, 1311 (1997).

10. P. Vandenberghe, J. Ceuppens, J. Immunolog. Meth. 127, 197 (1990).

11. M.B. Hallett, E.V. Davies, A.K. Campbell Cell Calcium 11, 655 (1990).

12. T. Springer Cell76, 301 (1994).

13. S.D. Rosen, C.R. Bertossi Curr. Opin. Cell Biol. 6, 663 (1994)

14. M. Lawrence, T. Springer J. Immunol. 151, 6338 (1993).

15. K. Fluri, G. Fitzpatrick, D.J. Harrison, Anal. Chem., 68, 4285 (1996).

16. S.D. Rosen, C.R. Bertossi Curr. Opin. Cell Biol. 6, 663 (1994).

17. V.A. Golovina, M.P. Blaustein Science 275, 1643 (1997).

18. M. Lawrence, T. Springer J. Immunol. 151, 6338 (1993). 